\title{
Crude Antigen from Taenia crassiceps Cysticercus Used as Heterologous Antigen in ELISA and in EITB for Neurocysticercosis Diagnosis of Patients from Paraná-Brazil
}

\author{
João Carlos Minozzo ${ }^{1}$, Juliana de Moura ${ }^{2}$, Sérgio Monteiro Almeida ${ }^{3}$ and Vanete Thomaz- \\ Soccol $^{2^{*}}$ \\ ${ }^{I}$ Centro de Produção e Pesquisa de Imunobiológicos; Secretaria de Estado da Saúde do Paraná; Piraquara - PR - \\ Brasil. ${ }^{2}$ Departamento de Patologia Básica; Universidade Federal do Paraná; Curitiba - PR - Brasil. ${ }^{3}$ Laboratório \\ de Virologia; Hospital de Clinicas; Universidade Federal do Paraná; Curitiba - PR - Brasil
}

\begin{abstract}
Neurocysticercosis (NCC), the cerebral presence of Taenia solium metacestode (Cysticercus cellulosae), is responsible for neurological disorders worldwide. In order to validate an immunodiagnosis for public-health patients in the State of Parana-Brazil, crude antigen of Taenia crassiceps metacestode (Cysticercus longicollis) was used as an alternative heterologous antigen to be used in ELISA and in electroimmunotransfer blotting (EITB) for active and inactive NCC diagnosis. Indirect ELISA was able to discriminate between active and inactive samples and presented high specificity and sensitivity. Any immunodominant band was able to distinguish the NCC stages, although the EITB showed 100\% specificity. The immunological results proved to be an important auxiliary toll for NCC diagnosis, mainly for public-health systems in developing countries, where either the neuroimage techniques are not accessible or the resources are scarce.
\end{abstract}

Key words: Neurocysticercosis, immunodiagnosis, ELISA, EITB, Cysticercus longicollis

\section{INTRODUCTION}

Neurocysticercosis (NCC), an important nervous system infection due to Cysticercus cellulosae, presents a world-wide distribution. Clinical symptoms are pleomorphic and dependent on the number, type and localization of cysticerci. Some patients can develop neurological deficits and epilepsy (Carpio, 2002; Takayanagui and Odashima, 2006). Its diagnosis is based on clinical, epidemiological, and immunological findings, but requires expensive techniques such as imaging analysis. In some countries such as Brazil, the costs for implementing and performing neuroimaging diagnostic are very high. *This

\footnotetext{
*Author for correspondence
}

necessitates the search for a cheaper and accurate diagnosis method as an appropriate surveillance mechanism (Ito, 2002; Flisser et al., 2006). Immunoassays using crude antigen from $C$. cellulosae could be used (Iudici Neto et al., 2007), although this presents some disadvantages such as cross reaction with other Cestodes, and the large amount of parasites necessary to obtain enough antigen (Pardini et al., 2002). Furthermore, the drawback in antigen production is to find naturally infected swine. Nowadays, this is rare due to management procedures imposed on pig raising. The alternative would be to infect them experimentally with $T$. solium eggs, but for that infrastructure and adult tapeworm are necessary, for it is a high risk activity and thus impracticable in large-scale. These facts stimulate the search for 
other sources of antigen for NCC diagnosis. A fox's parasite named Taenia crassiceps appeared to be a possible source when Freeman isolated cysticercus (C. longicollis) from rodents in 1962. This mutant strain, labeled ORF, reproduces asexually by exogenous budding inside the peritoneal cavity of mice. Keeping $C$. longicollis in laboratory could be a way of having an antigen source to be used in immunoassays for $C$. cellulosae because these parasites share antigenic elements in immunoelectrotransfer blottings EITB (Pardini et al., 2002). The search for antigens is rare in neurocysticercosis diagnosis (Flisser and Gyorkos, 2007) and immunodiagnosis is based, primarily, on the detection of antibodies (Schantz and Tsang, 2003) by ELISA and EITB (Dua and Aneja, 2006; Schantz, 2006). Studies have shown it is possible by ELISA and using different antigens to discriminate between active and inactive NCC, i.e., when the cysticercus is alive or inert, respectively (Molinari et al., 2002; Barcelos et al., 2005).

The aim of this work was to compare the experimental results obtained by ELISA and immunoblot assays using $C$. longicollis crude antigens and sera and cerebrospinal fluid (CSF) from patients with active, inactive NCC or with cysts in transitional phase, i.e., in degeneration, from the State of Paraná, Brazil.

\section{MATERIAL AND METHODS}

\section{Serum and cerebrospinal fluid (CSF)}

Serum from active $(n=23)$ and inactive $(n=9)$ neurocysticercosis (NCC) and CSF samples from patients with active $(n=46)$ and inactive $(n=24)$ disease were diagnosed through imaging and were collected at the Departamento de Virologia, Hospital de Clínicas - UFPR, in Curitiba-Brazil. The study protocol was approved by the Ethics committee on human research at that hospital according to Resolution 196/96 of the National Health Council, Ministry of Health, Brazil. CSF samples from 72 individuals with other neuropathologies (such as Hystoplasmosis, Behcet's disease, Harada's syndrome, etc.) were used as negative controls. The selection criteria was based on data obtained from clinical forms; image tests (radiography, tomography, NMR); and immunological, microbiological, and histopathological tests.

\section{Production of cysticercal antigen}

The antigens from $C$. longicollis were obtained as described by Vaz et al. (1996).

\section{Polyclonal antibodies}

In order to obtain polyclonal antibodies, each New Zealand rabbit was immunized subcutaneously with $C$. longicollis crude antigens following Minozzo et al. (2004)'s methodology. In short, in the first immunization, each animal received $1 \mathrm{mg}$ of antigen emulsified with Freund's complete adjuvant. Freund's incomplete adjuvant was used in booster doses (days 30 and 45). Serum samples were collected on days zero, $15,30,45,52$, and 60 after the beginning of immunization. The IgG fraction was purified by salting out with cold saturated ammonium sulphate and dialyzed against PBS.

\section{Indirect Elisa assay}

Specific cysticerci antibodies were detected in sera or CSF from NCC patients, and in controls sera by ELISA using crude antigen from $C$. longicollis. In short, an indirect ELISA was performed using microtiter plates coated overnight with $3.5 \mu \mathrm{g} / \mathrm{mL}$ of crude cyst antigen in $0.05 \mathrm{M}$ Coating Buffer $(\mathrm{pH}$ 9.6). The wells were washed with $0.05 \%$ Tween 20 in saline, blocked by incubation at $37^{\circ} \mathrm{C}$ for $1 \mathrm{~h}$ with $2 \%$ casein in PBS pH 7.4 and washed. Sera (1:12) or CSF (1:8) were diluted in incubation buffer $(0.25 \%$ casein, $0.05 \%$ Tween 20 , PBS 7.4$)$, distributed into the wells and incubated at $37^{\circ} \mathrm{C}$ for $1 \mathrm{~h}$; then the plate was washed and bound human IgG were detected by using an anti-human $\operatorname{IgG}$ peroxidase-conjugated (Sigma) diluted 1:1000. Incubation and washing were done and the enzymatic reaction was carried out by the addition of $0.04 \mathrm{mg} / \mathrm{ml} \mathrm{OPD}, 0.02 \%(\mathrm{v} / \mathrm{v}) \mathrm{H}_{2} \mathrm{O}_{2}$ in $0.1 \mathrm{M}$ citrate buffer ( $\mathrm{pH}$ 5.2) for $15 \mathrm{~min}$. The reaction was stopped by adding $2 \mathrm{~N}$ sulphuric acid and then the absorbance read at $492 \mathrm{~nm}$.

\section{Immunoecletrotransfer blot assay}

C. longicollis soluble proteins were diluted in sample buffer, boiled and separated along with Broad Ranger molecular weight markers (Biolabs), using a 12\% SDS-PAGE gel. The gels were transferred to Hybond nitrocellulose membrane (Amershan Biotech). Subsequently, nitrocellulose strips were blocked with $3 \%$ non-fat milk in PBS ( $\mathrm{pH} \mathrm{7.4)} \mathrm{for} 1 \mathrm{~h}$ at room temperature. After washing $(0.05 \%$ Tween 20 - PBS (PBS-T), the membranes were incubated with the patients' 
CSF (1:4) or serum samples (1:4) diluted in PBS-T for $4 \mathrm{~h}$ at room temperature. The strips were washed and incubated for $2 \mathrm{~h}$ at room temperature with anti-human $\mathrm{IgG}$ peroxidase-conjugated (Sigma A-0170) diluted 1:2000 in PBS-T. The strips were washed in PBS-T and developed in $0.06 \%$ DAB and $0.01 \%(\mathrm{v} / \mathrm{v}) \mathrm{H}_{2} \mathrm{O}_{2} 30 \%$ in PBS. The reaction was stopped after washing with PBS. Serum or CSF samples were considered positive when one or more bands with $13,14,18,21,24$, $38-42,50 \mathrm{kDa}$ (Tsang et al., 1989) and/or 47-52, 56, 64-68 and 126-155 kDa (Shiguekawa et al., 2000) showed reactivity.

\section{Cysticerci antigen detected by ELISA}

In order to evaluate the possibility of detecting $C$. cellulosae antigens in CSF, an ELISA was performed. For this, a 96-well multititer plate was coated overnight with a pool of CSF from NCC patients (diluted 1:500 in 0.05 M Coating Buffer, $\mathrm{pH}$ 9.6). The washing and blocking was done and C. longicollis polyclonal antibodies from rabbits (diluted 1:800 in incubation buffer) were added. Subsequently, the plate was washed and bound rabbit $\mathrm{IgG}$ were detected by anti-rabbit $\mathrm{IgG}$ peroxidase-conjugated (Sigma A-6154) diluted
1:4000. The enzymatic reaction was detected as described above.

\section{RESULTS}

The performance of $C$. longicollis antigen as heterologous antigen in the immunodiagnosis of neurocysticercosis caused by active, inactive or in degeneration cysticerci in patients from ParanaBrazil was evaluated.

\section{Indirect ELISA}

The indirect ELISA results of serum from NCC patients and control group (patients with other neuropathologies) using crude $C$. longicollis as antigen are presented in Fig. 1. Samples with absorbance equal to or higher than 0.096 of the cut-off value (non-reactive samples plus two standard deviations) were considered positive. Twenty two (96\%), sera out of 23 active NCC patients, 1 (20\%) out of 5 samples from patients with inactive form, and 3 (75\%) out of 4 sera from NCC patients with cysticercus in degeneration showed reactivity against $C$. longicollis antigen.

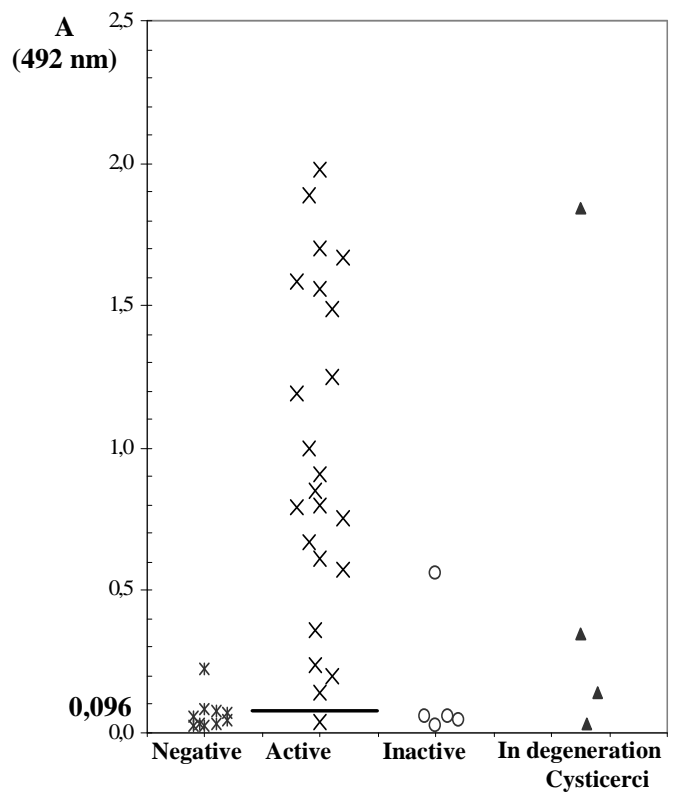

Figure 1 - Indirect ELISA using $C$. longicollis antigen with serum samples from NCC patients $(n=32)$ subdivided in active $(\times, n=23)$, inactive $(a, n=5)$ and in degeneration $(\boldsymbol{\Delta}, n=4)$ cysts and from negative group $(*, n=10)$. The bar means cut off value. 


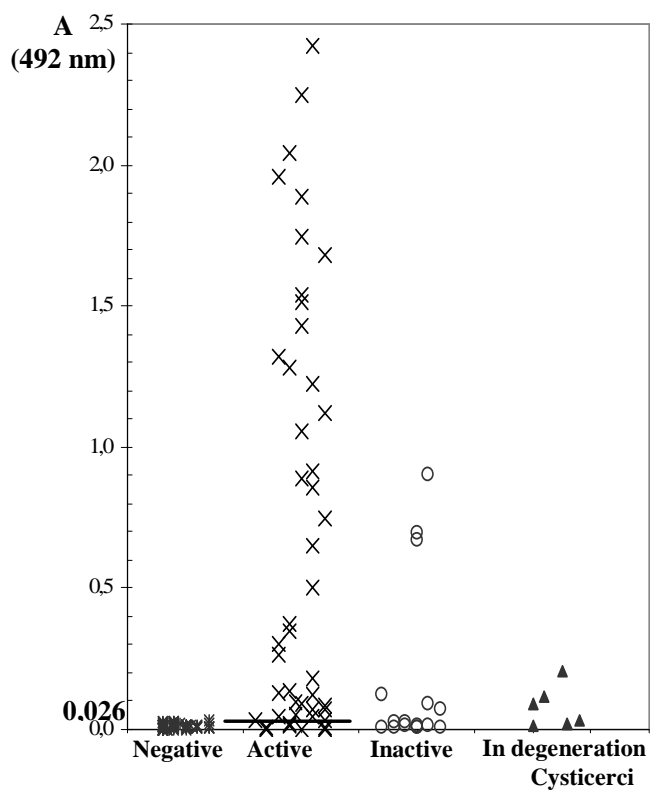

Figure 2 - Indirect ELISA using C. longicollis crude antigen with CSF samples from NCC patients $(n=68)$ subdivided in active $(\times, n=46)$, inactive $(\alpha, n=16)$ and in degeneration $(\boldsymbol{\Delta}, \mathrm{n}=6)$ cysts and from negative group $(*, \mathrm{n}=72)$. The bar means cut off value.

The indirect ELISA results obtained for $68 \mathrm{CSF}$ from NCC patients and for 72 CSF samples from control group are shown in the Fig. 2. Samples that produced absorbance readings above the cut-off (0.026) were considered positive. Thirty-nine (85\%) out of 46 CSF samples from patients with active cysticercus, 8 (50\%) out of 16 samples from patients with inactive form, and $4(66 \%)$ out of 6 samples from NCC patients with cysticercus in degeneration reacted with $C$. longicollis soluble antigen in the ELISA.

Specificity, sensitivity and accuracy values of indirect ELISA for sera and CSF samples

The efficacy of indirect ELISA for active, inactive NCC and in degeneration cysts using serum or CSF samples could be corroborated through the analysis of specificity, sensitivity, and accuracy values for indirect ELISA. The ELISA sensitivity using serum was higher (96 and 75\%) than CSF ELISA (85 and 67\%) for active and in degeneration cysts, although under the same conditions the specificity of serum ELISA was lower (Table 1). On the other hand, although the assays using serum or CSF from patients with calcified cystcercus had low values, CSF ELISA was more sensitive (50\%) than ELISA using serum $(20 \%)$.

\section{Cysticercus antigen detection}

In order to enhance the diagnostic accuracy, antigens from $C$. cellulosae were studied in patients' CSF using anti $C$. longicollis polyclonal antibodies from rabbits. Samples whose absorbance values were equal to or higher than the cut-off (0.269) were considered positive. As expected, the ELISA's sensitivity for active neurocysticercosis was higher $(67 \%)$ than the results obtained for calcified, i.e., inactive NCC $(10 \%)$ and in degeneration cysticerci (29\%) (Table 2).

Fig. 3 showed that $30 \mathrm{CSF}$ samples out of 45 patients $(66.7 \%)$ with active cysts, 2 out of 18 samples $(11 \%)$ from inactive form and 2 out of 5 (40\%) NCC with cysticercus in degeneration process were positive for the presence of $C$. cellulosae antigen in the cerebrospinal fluid. 
Table 1 - Indirect ELISA assay in sera and CSF for inactive, active and in degeneration cysticerci using crude heterologous $C$. longicollis as antigen. Rates of specificity (Sp), sensitivity (Ss), accuracy (A) and Positive or Negative Predictive Value (PPV) and (NPV) are indicated, respectively.

\begin{tabular}{lcccccc}
\hline NCC & $(\%)$ & Sp & Ss & Acc & PPV & NPV \\
\hline Inactive & & 90 & 20 & 67 & 50 & 69 \\
In degeneration & Sera & 90 & 75 & 86 & 75 & 90 \\
Active & & 90 & 96 & 94 & 96 & 90 \\
& & 93 & 50 & 84 & 67 & 87 \\
Inactive & & 93 & 67 & 91 & 50 & 96 \\
In degeneration & CSF & 93 & 85 & 89 & 91 & 88 \\
Active & & & & & \\
\hline
\end{tabular}

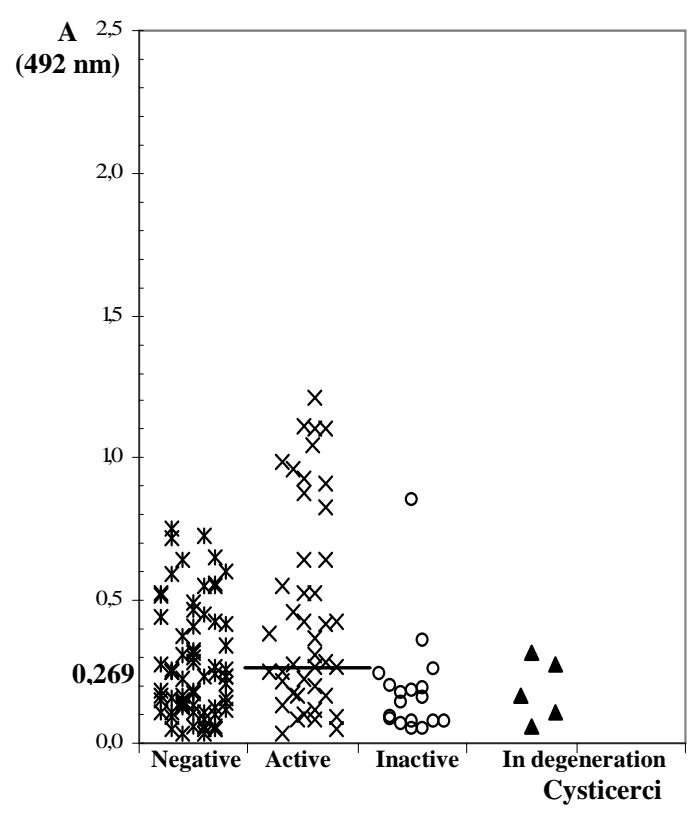

Figure 3 - ELISA results for detection of C. cellulosae antigens in CSF samples from NCC patients $(n=68)$ classified as active $(\times, n=45)$, inactive $(a, n=18)$ and in degeneration $(\boldsymbol{\Lambda}, \mathrm{n}=5)$ cysts and from negative group $(*, n=72)$, i.e, from patients with other neuropathologies. The bar means cut off value.

Table 2 - Cysticerci antigen detection in CSF for inactive, active and in degeneration cysticercus using polyclonal antibodies from rabbits immunized with crude antigen of $C$. longicollis. Rates of specificity (Sp), sensitivity (Ss), accuracy (A) and Positive or Negative Predictive Value (PPV) and (NPV) are showed, respectively.

\begin{tabular}{lcccccc}
\hline NCC & $(\%)$ & Sp & Ss & Acc & PPV & NPV \\
\hline Inactive & & 61 & 10 & 50 & 6.7 & 71 \\
In degeneration & CSF & 61 & 29 & 58 & 6.7 & 90 \\
Active & & 61 & 67 & 63 & 52 & 75 \\
\hline
\end{tabular}




\section{Specific protein recognized by EITB}

According to Tsang (1989) and Shiguekawa (2000), the results of serum or CSF samples could be considered positive when one or more bands with $13,14,18,21,24,38-42,50 \mathrm{kDa}$ and/or 47$52,56,64-8$ and $126-155 \mathrm{kDa}$, respectively, showed reactivity. In the EITB using $C$. longicollis as heterologous antigen, $8(20 \%)$ out of $40 \mathrm{CSF}$ samples from patients with active NCC, $8(61.5 \%)$ out of 13 from patients with inactive form, and 2 (40\%) out of 5 samples from patients with cysts in degeneration were not reactive.

On the other hand, CSF from 72 patients with other neuropathologies reacted with any protein; there was not false positive, i.e., there was $100 \%$ specificity. The CSF from patients with active NCC manifested a higher reactivity frequency (Fig. 4) of the proteins of $97 \mathrm{kDa}$ and $140 \mathrm{kDa}$ (97\%), $123 \mathrm{kDa}(75 \%)$, and $150 \mathrm{kDa}(84 \%)$. The CSF samples from patients with cysts in degeneration process reacted only with high molecular weight bands $(76-149 \mathrm{kDa})$.

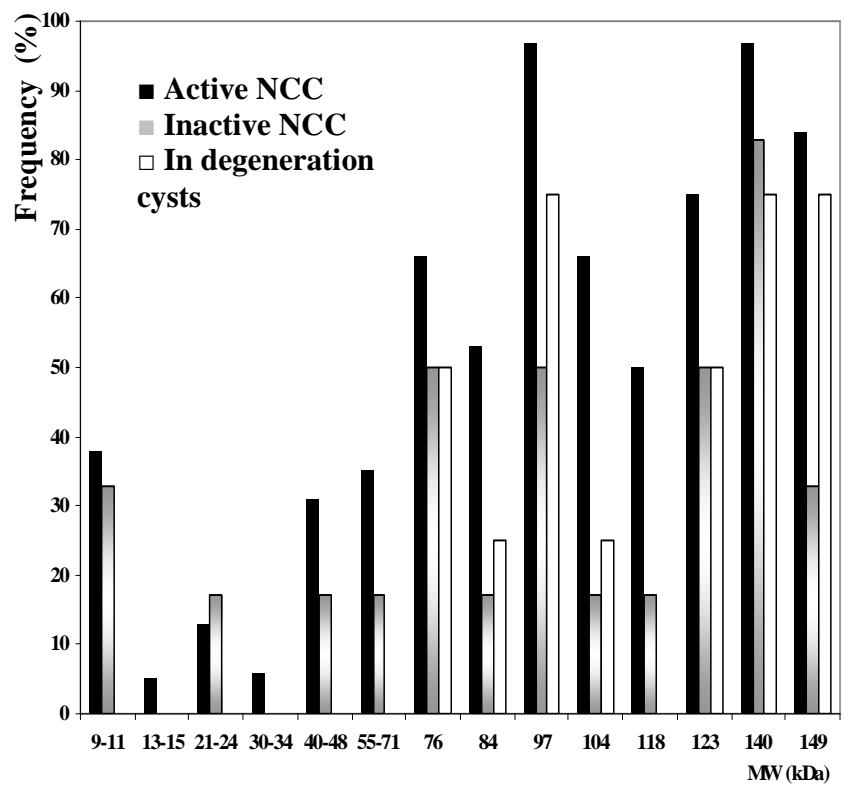

Figure 4 - Reactivity frequency of immunodominant proteins recognized by CSF antibodies from patients with active NCC $(\boldsymbol{\square}, \mathrm{n}=32)$, inactive $\mathrm{NCC}(\boldsymbol{\square}, \mathrm{n}=8)$ and in degeneration cysticerci $(\square, \mathrm{n}=3)$. Note: The frequency was calculated considering only positives samples.

The immunoblotting using serum was done in the same way, but only $19(82.6 \%)$ out of 23 NCC active patients were positive according to Tsang (1989) and Shiguekawa (2000). Serum from patients with active NCC reacted with high frequency with the proteins of high molecular weight such as 97 and $84 \mathrm{kDa}(75 \%), 104-123$ $\mathrm{kDa}(83 \%)$, and $140 \mathrm{kDa}(92 \%)$ (Fig.5).

There was some reactivity with proteins around 50 $\mathrm{kDa}$ with a frequency of $42 \%$, and no reactive sample from patients with cysticerci in degeneration, although one serum from a patient with an inactive NCC form reacted strongly with the $52 \mathrm{kDa}$ band.

Eleven serum samples from patients with other neuropatologies - excluding NCC - were tested by EITB using $C$. longicollis as antigen, and they showed no reactivity with low molecular weight protein. On the other hand, three out of 11 serum control samples (28\%), all of them $(100 \%)$ and six $(55 \%)$ serum samples reacted with 148,140 , and $123 \mathrm{kDa}$ bands, respectively. The protein bands with 52, 65, 71, 84, and $97 \mathrm{kDa}$ were recognized by at least one serum from the control group.

\section{DISCUSSION}

The big problem in implementing control and proposing eradication programs for neurocysticercosis is the difficulty to establish an early and unequivocal diagnosis due to the inespecificity of the clinical manifestation and to the inaccurate interpretation of neuroimaging 
findings due to similarities between these lesions and those of tuberculomas, brain tumors, and arteriovenous malformations (Dua and Aneja, 2006).

Furthermore, the costs for performing neuroimaging techniques are very high, mainly for the public-health system. For routine laboratory tests, the best choice for a NCC screening could be the use of immunoassays that combines accuracy, sensitivity, and reasonability (Ito, 2002; Flisser et al., 2006). The results of an immunodiagnostic test for NCC could increase the probability of getting the correct diagnosis.

A step further in this direction could be to use crude antigen from C. cellulosae (Silva et al., 2000; Iudici Neto et al., 2007; Parija et al., 2007). However, it is very difficult to obtain enough quantities of an antigen as that depends either on finding naturally infected swine or infecting them experimentally with $T$. solium eggs.

$\begin{array}{lllllllllllll}1 & 2 & 3 & 4 & 5 & 6 & 7 & 8 & 9 & 10 & 11 & 12 & \mathrm{C}\end{array}$
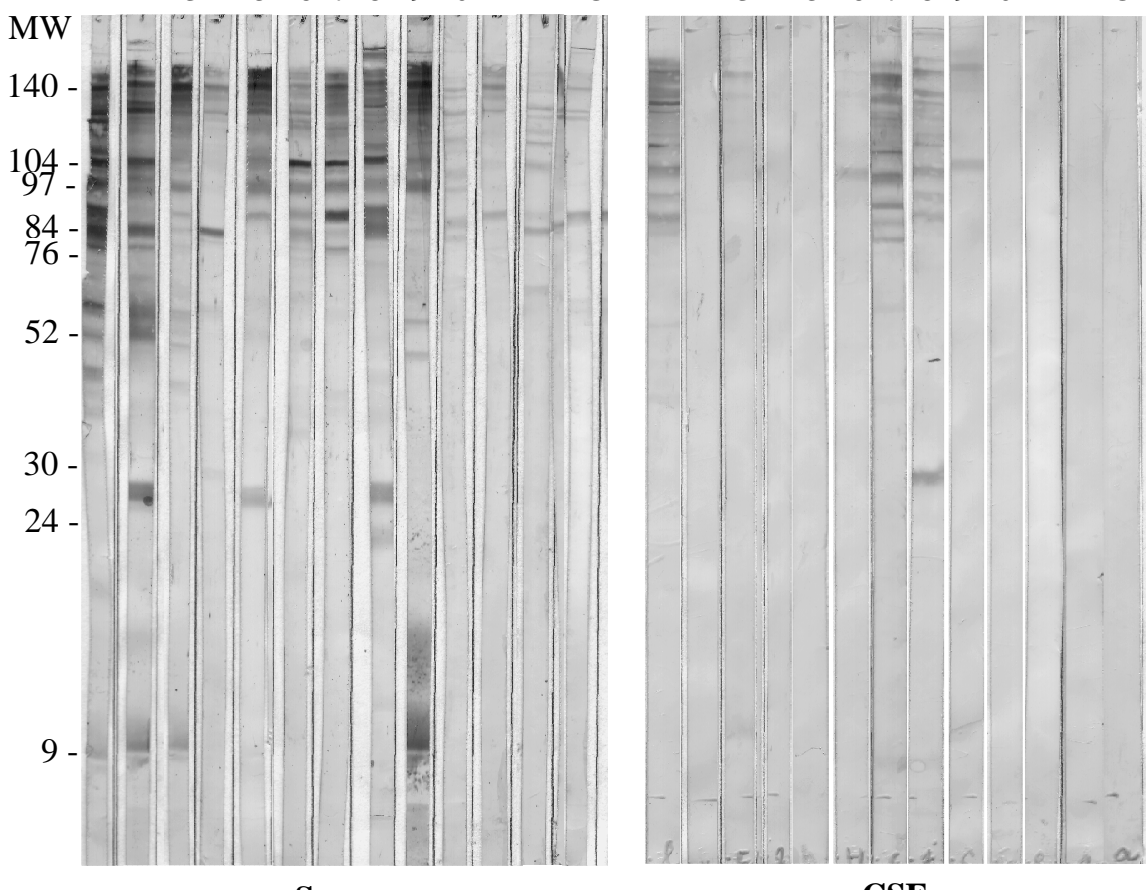

Figure 5 - Illustration of blot immunoreactivity of the serum and the CSF from 12 patients with active NCC and one of eleven patients with other neuropathologies as control group (C) tested in the ELISA. The reactivity of serum and CSF were analyzed individually using lanes containing Cysticercus longicollis crude extract as antigen. Proteins were separated by SDS-PAGE on a $12 \%$ gel under reducing conditions. Molecular weight proteins are indicated in the left in kilodaltons $(\mathrm{kDa})$.

Several studies have shown that $C$. longicollis could replace $C$. cellulosae because both parasites shared antigenic elements able to be used in ELISA or immunoblottings (Vaz et al., 1996; Bueno et al., 2000; Pardini et al., 2002; Peralta et al., 2002; Ishida et al., 2006). Therefore, the use of this heterologous antigen may contribute for seroepidemiologic studies to evaluate the complex taeniasis/cysticercosis (Vaz et al., 1996; 1997, Sciutto et al., 2000, Ito, 2000). Furthermore, studies have shown that immunoassays were able to detect whether the patients presented alive or inactive cysticerci (Molinari et al., 2002, Barcelos et al., 2005, 2007). In order to evaluate and confirm the epidemiological data of neurocysticercosis in the State of Paraná, Brazil, C. longicollis crude extract was used as heterologous antigen of C. cellulosae in ELISA and EITB assay of patients with different 
evolutionary stages of cysticerci (Sotelo et al., 1988) diagnosed through neuroimages features.

In the present work, samples of CSF and serum from patients with NCC confirmed by computed tomography were analyzed. C. cellulosae antigens were captured by ELISA using rabbit polyclonal antibodies produced against its heterologous antigens, $C$. longicollis. The specificity and the sensitivity of those immunoassay results were observed as well as their performance when cerebrospinal fluid (CSF) or serum was used. The specificity of indirect ELISA was 93 and $90 \%$ for CSF and serum, respectively. The same assay was more sensitive when serum $(96 \%)$ was used as compared to CSF (85\%) from patients with active NCC.

The reactivity of serum or CSF from patients with inactive, i.e., calcified cysticercus could be explained by the presence of antibodies that could persist for a long time after the parasite was eliminated by immune mechanisms and/or therapeutic drugs (Harrison, et al., 1989; Garcia et al., 1997; Sciutto et al., 2007). Even with CSF samples from patients with active NCC, the antigen detection by ELISA did not present good results. Its specificity and sensitivity were only 61 and $67 \%$, respectively. In this immunoassay, only $66.7 \%$ of samples from patients with active cysts were reactive. Its sensitivity for active NCC was higher $(67 \%)$ than the results obtained for inactive NCC (10\%) and in degeneration cysticerci (29\%). Due to low specificity (61\%), this assay must require the concomitant use of EITB or indirect ELISA.

As expected, 80 and $60 \%$ of CSF from patients with active NCC and cysts in degeneration process, respectively, showed reactivity with $C$. longicollis crude antigen in an immunoblotting, while, as demonstrated by other studies, only $38.5 \%$ samples from patients with calcified lesion form showed any reactivity (Garcia, 1997). The specificity of that immunoassay was $100 \%$ as there were not false positives among CSF samples from patients with other neuropathologies who were used as control group.

Antibodies from serum and CSF of NCC patients detected peptides more frequently with high molecular weight bands (97 kDa, $123 \mathrm{kDa}, 140$ $\mathrm{kDa}$, and $150 \mathrm{kDa}$ ). However, the serum and the CSF samples from control group reacted with proteins equal or above $76 \mathrm{kDa}$.
Therefore, as argued by Barcelos et al. (2007), the high molecular weight bands present strong cross reaction and must not be used for NCC diagnosis. Similar results were obtained with the CSF samples from patients with cysts in degeneration process, which reacted exclusively with high molecular weight proteins. According to observations of Aluja et al. (1996) about animals infected with cysticerci, low molecular weight proteins $(13-18 \mathrm{kDa})$ were the most immunogenic antigens at the beginning of the disease whereas, in later phases, antibodies were produced against medium molecular weight proteins $(24,42$, and $50 \mathrm{kDa})$.

In the present immunoblotting for active NCC, the low molecular weight proteins (9-12 kDa, 24-32 $\mathrm{kDa}$ ) and peptides between $45-70 \mathrm{kDa}$ had higher frequencies in the serum than in the CSF. These results were contrary to previous studies by Barcelos and colleagues (2007), who used $C$. cellulosae as antigen and found higher frequencies with CSF than with serum. Discordant results corroborated other studies that showed that differences in reactivity could be related to immunological factors, localization and development phase of cysts, especially with existing immune-evasive mechanisms (Sciutto et al, 2007). Due to complex and diverse core epitope from antigens present in the parasite, the immune system could respond to distinct forms (Flisser, 2002).

There are other conflicting reports also. Chung (1999) has shown that a $10 \mathrm{kDa}$ recombinant molecule (CyDA) with high homology with $C$. longicollis protein was reactive in $97 \%$ of active NCC samples and had $98 \%$ specificity. These results were not confirmed in the present work in active NCC. It was found that the band between 9 and $12 \mathrm{kDa}$ had only a $38 \%$ reactivity frequency and $79 \%$ specificity. Hancock et al., (2004) showed that band $50 \mathrm{kDa}$ had both high sensitivity and specificity. However, Furrows et al.(2006) showed there was an heterogeneous reactivity in NCC immunodiagnosis and, for this, single band findings in an EITB must be interpreted with special caution. Espíndola (2000) observed that hyperimmune mouse BALB/c serum against crude antigen of $T$. crassiceps was able to recognize peptides of 18 and 12-14 $\mathrm{kDa}$ of $T$. crassiceps. In the same experiment, it was observed that the 15 , 70 , and $94 \mathrm{kDa}$ antigens of $T$. solium were not specific, since they reacted with serum from negative control animals. Rodriguez-Hidalgo et al. 
(2006) analyzed serum of infected swine and obtained high reactivity on 50 and $39-42 \mathrm{kDa}$ protein bands.

As reported by Molinari et al. (2002), the indirect ELISA results showed that samples from patients with alive cysticercus had higher absorbance than samples from patients whose cysts were calcified or in transitional stages, but this distinction could not be made by immunoblotting. Although different immunodominant proteins were found in the EITB, any band was able to discriminate the different forms of neurocysticercosis. The methodologies for antibody detection in serum and CSF by ELISA and immunoblotting techniques demonstrated that they should be used in the diagnosis of neurocysticercosis, specially when associated and combined with clinical and neuroimage examinations.

In the analysis of the patients' medical records, it was possible to observe that the diagnostic conclusions were based on the clinical aspect, in the image exams, in the biochemical exam of CSF, and in the repetition of these exams at different times, submitting the patient to expensive and traumatic procedures. The neuroimages were rarely absolutely positive in showing that the observed images refer to cysticerci. The interpretation of images usually included words like "suggestive, similar, seemed, compatible or with aspect of...", i.e., they were inconclusive most of the time.

Hence, the immunoassays using crude $C$. longicollis antigen could improve diagnosis reliability because of their high sensibility and absence of false positives. In different countries, immunological tests (Flisser and Gyorkos, 2007; Prabhakaran et al., 2008) have proved to be an important auxiliary instrument in the diagnosis, mainly for public-health institutions in endemic areas where the diagnosis by image is not accessible or resources are scarce.

\section{ACKOWLEDGMENTS}

Authors thank CNPq for grant no 303271b/2005-1.

\section{RESUMO}

Neurocisticercose (NCC), causada pela presença do metacestódeo do parasito Taenia solium
(Cysticercus cellulosae) no sistema nervoso central, é uma doença mundialmente conhecida como responsável por distúrbios neurológicos. Com o objetivo de validar um imunodiagnóstico para pacientes da rede pública do estado do Paraná-Brasil, o extrato bruto do metacestódeo de $T$. crassiceps (C. longicollis) foi produzido $\mathrm{e}$ utilizado como antígeno heterólogo para o diagnóstico de NCC ativa e inativa utilizando-se ELISA e eletroimunotransferência (EITB). O ensaio de ELISA indireto foi capaz de discriminar a forma ativa e inativa da NCC, apresentando alta especificidade e sensibilidade. Ao se utilizar EITB, nenhuma proteína foi imunodominante de forma a distinguir os diferentes estágios da NCC, embora o ensaio tenha tido $100 \%$ de especificidade. Os resultados mostram que os ensaios imunológicos podem ser uma ferramenta auxiliar importante para o diagnóstico da NCC, principalmente para o sistema público de saúde, cujo diagnóstico por imagem não é acessível ou cujos recursos financeiros são escassos.

\section{REFERENCES}

Aluja, A. S., Villalobos, A. N. M., Plancarte, A., Rodarte, L. F., Hernandez, M., Sciutto, E. (1996), Experimental Taenia solium cysticercosis in pigs: characteristics of the infection and antibody response. Vet Parasitol, 61, 49-59.

Barcelos, I. S., Ferreira, M. S., Moura, L. P., Biondi, G. F., Costa-Cruz, J. M. (2005), Use of the paired samples (cerebrospinal fluid and serum) in immunodiagnostic of active and inactive human neurocysticercosis. Mem Inst Oswaldo Cruz, 100, 4279.

Barcelos, I. S. D., de Moura, L. P., Costa, V. P., Ferreira, M. S., Costa-Cruz, J. M. (2007), Taenia solium metacestode immunodominant peptides recognized by $\mathrm{IgG}$ antibodies in cerebrospinal fluid and serum paired samples from patients with active and inactive neurocysticercosis. Mem Inst Oswaldo Cruz, 102, 713-717.

Bueno, E. C., Vaz, A. J., Machado, L. D., Livramento, J. A., Mielle, S. R. (2000), Specif Taenia crassiceps and Taenia solium antigenic peptides for neurocysticercosis immunodiagnosis using serum samples. J Clin Microbiol, 38, 146-51.

Carpio, A. (2002), Neurocysticercosis: an update. Lancet Infect Dis, 2, 751-762.

Chung J. Y., Bahk, Y. Y., Huh, S., Kang, S. Y., Kong, Y., Cho, S. Y. (1999), A recombinant 10-kDa protein of Taenia solium metacestodes specific to active neurocysticercosis. J Infect Dis, 180, 1307-1315. 
Dua, T., Aneja, S. (2006), Neurocysticersosis: management issues. Indian Pediatr, 43, 227-25.

Espíndola, N. M., Gaspari, E. N., Nakamura, P. M., Vaz, A. J. (2000), Cross-reactivity of anti-Taenia crassiceps cysticerci immune antibodies with Taenia solium antigens. Vet Parasitol, 89, 321-326.

Flisser, A., Correa, D., Evans, C. A. W. (2002), Taenia solium cysticercosis: new revisited immunological aspects. In: Singh, G., Prabhakar, S., eds. Taenia solium cysticercosis. Wallingford, UK: CABI Publishing, pp 24-44.

Flisser, A., Rodriguez-Canul R., Willingham, A. L., (2006), Control of the taeniosis/cysticercosis complex: Future developments. Vet Parasitol, 139, 283-292.

Flisser, A., Gyorkos, T. W. (2007), Contribution of immunodiagnostic tests to epidemiological/ intervention studies of cysticercosis/taeniosis in Mexico. Parasite Immunol, 29, 637-649.

Freeman, R. S. (1962), Studies in the biology of Taenia crassiceps. Can J Zool, 40, 969-90

Furrows, S. J., McCroddan, J., Bligh W. J., Chiodini, P. (2006), Lack of specificity of a single positive $50-\mathrm{kDa}$ band in the electroimmunotransfer blot (EITB) assay for cysticercosis. Clin Microbiol Infect, 12, 459-462.

Garcia, H. H., Gilman, R., Catacora, M., Verastegui, M., Gonzalez, A. E., Tsang, V. C., (1997), Serological evolution of neurocysticercosis patients after antiparasitic therapy. J Infect Dis, 175, 486-489.

Hancock, K., Pattabhi, S., Greene, R. M., Yushak, M. L., Williams, F., Khan, A., Priest, J. W., Levine, M. Z., Tsang, V. C. (2004), Characterization and cloning of GP50, a Taenia solium antigen diagnostic for cysticercosis. Mol Biochem Parasitol, 133,115-24.

Harrison, L. J. S., Joshua, G. W. P., Wright, S. H., Parkhouse, R. M. E., (1989), Specific detection of circulating surface/secreted glycoproteins of viable cysticerci in Taenia saginata cysticercosis. Parasite Immunol, 11, 351-370.

Ishida, M. M., Peralta, R. H., Livramento, J. A., Hoshino-Shimizu, S., Peralta, J. M., Vaz, A. J. (2006), Serodiagnosis of neurocysticercosis in patients with epileptic seizure using ELISA and immunoblot assay. Rev Inst Med Trop Sao Paulo, 48, 343-6.

Ito, A. (2002), Serologic and molecular diagnosis of zoonotic larval cestode infections. Parasitol Int, 51, 221-235.

Iudici Neto F., Pianetti-Filho G., Araújo, R. N., Nascimento E. (2007), Immunodiagnosis of human neurocysticercosis by using semi-purified scolex antigens from Taenia solium cysticerci. Rev Soc Bras Med Trop, 40, 163-169.

Minozzo, J. C., Thomaz-Soccol V., Olortegui, C. C., Soares, V. E., Costa, A. J. (2004), Teste imunoenzimático para diagnóstico da cisticercose bovina e estudo da cinética de produção de anticorpos contra Cysticercus bovis. Ciência Rural, 34, 857-864.

Molinari, J. L., García-Mendoza, E., de la Garza, Y., Ramírez, A., Sotelo, J., Tato, P. (2002),
Discrimination between active and inactive neurocysticercosis by metacestode excretory/secretory antigens of Taenia solium in an enzyme-linked immunosorbent assay. Am J Trop Med Hyg, 66, 77781.

Pardini, A. X., Peralta, R. H., Vaz, A., Machado, L. R., Peralta, J. M., (2002), Use of Taenia crassicepscysticercus antigen preparations for detection of antibodies in cerebrospinal fluid samples from patients with neurocysticercosis (Taenia solium). Clin Diag Lab Immunol, 9, 190-193.

Parija, S. C., Sahu, P. S., Dhanya, H. (2007), Detection of cysticercus antigens and antibodies in cerebrospinal fluid of patients with chronic meningitis. Rev Inst Med Trop Sao Paulo, 49, 331-4.

Peralta, R. H. S., Vaz, A. J., Pardini, A., Macedo, H. W. Machado, L. R., De Simone, S. G., Peralta, J. M. (2002), Evaluation of na antigen from Taenia crassiceps cysticercus for the serodiagnosis of neurocysticercosis. Acta Trop, 83, 159-168.

Prabhakaran, V., Raghava, M. V., Rajshekhar, V., Muliyil, J., Oommen, A. (2008), Seroprevalence of Taenia solium antibodies in Vellore district, south India. Trans $R$ Soc Trop Med Hyg, 102, 246-50.

Rodriguez-Hidalgo, R., Benítz-Ortiz, W., Praet, N., Saa, L. R., Vercruysee, J., Brandt, J., Dorny, P. (2006), Taeniasis-cysticercosis in Sourthen Ecuador: assessment of infection status using multiple laboratory diagnostic tools. Mem Inst Oswaldo Cruz, 101, 779-782.

Schantz, P. M., Tsang, V. C. W. (2003), The US Centers for Disease Control and Prevention (CDC) and research and control of cysticercosis. Acta Trop, 87, 161-163.

Schantz, P.M. (2006), Progress in diagnosis, treatment and elimination of echinococcosis and cysticercosis. Parasitol Int, 55, 7-13.

Sciutto, E., Fragoso, G., Fleury, A., Laclette, J. P., Sotelo, J, Aluja, A., Vargas, L., Larralde, C. (2000), Taenia solium disease in human and pigs: an ancient parasitosis disease rooted in developing countries and emerging as a major health problem of global dimensions. Microbes and Infec, 2, 1875-1890.

Sciutto, E., Chavarria, A., Fragoso, G., Fleury, A., Larralde, C. (2007), The immune response in Taenia solium cysticercosis: protection and injury. Parasite Immunol, 29, 621-636.

Silva, A. D. T., Quagliato, E. M. A. B., Rossi, C. L. (2000), A quantitative enzime-linked immunosorbent assay (ELISA) for the immunodiagnosis of neurocysticercosis using a purified fraction from Taenia solium cysticerci. Diag Microbiol Infect Dis, 37, 87-92.

Shiguekawa, K. Y., Mineo, J. R., de Moura, L. P., Costa-Cruz, J.M. (2000), ELISA and western blotting tests in the detection of $\operatorname{IgG}$ antibodies to Taenia solium metacestodes in serum samples in human neurocysticercosis. Trop Med Int Health, 5, 443-9. 
Sotelo, J., Guerrero, J., Rubio, F. (1988), A new classification based on active and inactive forms. Arch Intern Med, 148, 442-45.

Takayanagui, O. M., Odashima, N. S. (2006), Clinical aspects of neurocysticercosis. Parasitol Int, 55, Suppl:S 111-5.

Tsang, V. C. W., Brand, J. A., Boyer, A. E. (1989), Enzyme-linked immunoelectrotransfer blot assay and glycoprotein antigens for diagnosing human cysticercosis (Taenia solium). J Infect Dis, 159, 50-59. Vaz, A. J., Nakamura, P. M., Camargo, M. E., Camargo, E. D., Ferreira, A. W. (1996), Dot-Elisa for the detection of anti-Cysticercus cellulosae antibodies in cerebrospinal fluid using a new solid phase (resin- treated polyester fabric) and Cysticercus longicollis antigens. Rev Inst Med Trop, 38, 391-396.

Vaz, A. J., Nunes, C. M., Piazza, R. M. F., Livramento, J. A., Da Silva, M. V., Nakamura, P. M., Ferreira, A. W. (1997), Immunoblot with cerebrospinal fluid from patients with neurocysticercosis using antigen from cysticerci of Taenia solium and Taenia crassiceps. Am J Trop Med Hyg, 57, 354-357.

Received: May 25, 2007; Revised: May 20, 2008; Accepted: September 28, 2008. 
PÁGINA

EM

BRANCO 